\title{
Polycrystalline Wüstite Surface Observed by STM and LEED
}

\author{
Yohsuke MASAKI, ${ }^{1)}$ Takashi WATANABE, ${ }^{1)}$ Toru YAMASHITA, ${ }^{2)}$ Miyuki HAYASHI ${ }^{11}$ and Kazuhiro NAGATA ${ }^{1)}$ \\ 1) Department of Chemistry and Materials Science, Tokyo Institute of Technology, 2-12-1 Ookayama, Meguro-ku, Tokyo 152- \\ 8552 Japan. $\quad$ 2) Mesaplexx Pty Ltd., 7 Clunies Ross Court, Eight Mile Plains QLD 4113, Australia.
}

(Received on September 10, 2008; accepted on October 20, 2008)

\begin{abstract}
After annealing at $1273 \mathrm{~K}$ in UHV chamber to remove adsorbed molecule, the surface crystal structure and the composition of polycrystalline $\mathrm{Fe}_{1-x} \mathrm{O}$ were analyzed at room temperature using STM, LEED and AES. The $\mathrm{Fe}_{1-x} \mathrm{O}$ sample was prepared by oxidizing an polycrystalline electrolytic iron strip. The $\mathrm{Fe}_{1-x} \mathrm{O}$ surface consists of facets, where many steps like zig-zag shape are arranged. The mesh-like structure, of which periodicity is about $0.8-1.3 \mathrm{~nm}$, was observed on the terrace. The facets are (001) planes of $\mathrm{Fe}_{1-x} \mathrm{O}_{\text {, }}$ and the step direction is $\langle 110\rangle$ by LEED measurement. The mesh-like structure is considered as the defect clusters derived from nonstoichiometry.
\end{abstract}

KEY WORDS: wüstite; polycrystal; surface structure; STM; LEED.

\section{Introduction}

On the reduction process of wüstite $\left(\mathrm{Fe}_{1-x} \mathrm{O}\right)$ as one of the intermediate products in the iron making processes, Yamashita et al. ${ }^{1)}$ has reported from the in-situ observation using a high temperature optical microscope that the reduction of $\mathrm{Fe}_{1-x} \mathrm{O}$ on the surface consists of complicated mechanisms which depend on the partial pressure of $\mathrm{CO}$ and reaction temperature. They concluded that the elementary steps controlling the reaction near the surface, e.g. adsorption and diffusion of $\mathrm{CO}$ gas, depend on the partial pressure and temperature. In order to verify the controlling steps of the reaction on the surface, however, the in-situ observation of the reduction of the $\mathrm{Fe}_{1-x} \mathrm{O}$ surface is required in a small scale of the nano order or atomic size. For the observation of the reaction on the surface in the nano order size, it is very important to clarify the atomic arrangements and defects on the surface in equilibrium.

The surface crystal structure of the $\mathrm{Fe}_{1-x} \mathrm{O}$ film grown on the Pt and Ru substrates was studied using a scanning tunnelling microscope (STM) or a low energy electron diffraction (LEED). ${ }^{2-4)}$ After annealing the bulk Fe substrates in an oxygen atmosphere $\left(10^{-8}-10^{-9} \mathrm{~atm}\right)$, the $\mathrm{Fe}_{1-x} \mathrm{O}(001)-$ $(1 \times 1)$ on $\mathrm{Fe}(001)^{5-7)}$ and $\mathrm{Fe}_{1-x} \mathrm{O}(111)-\mathrm{p}(2 \times 2)$ on $\mathrm{Fe}(110)^{8)}$ were observed using LEED and Auger electron spectroscopy (AES) in the initial stage of oxidation. These surface structures may differ from the surface structure on the bulk $\mathrm{Fe}_{1-x} \mathrm{O}$. The $\mathrm{Fe}_{1-x} \mathrm{O}$ films are so thin that the surface structures are affected by the strain caused by the misfit between the film and substrate. On the other hand, there are only limited reports on the surface crystal structure of bulk $\mathrm{Fe}_{1-x} \mathrm{O}$. Nagata et al. ${ }^{9)}$ have observed three types of polycrystalline $\mathrm{Fe}_{1-x} \mathrm{O}$ surface with different concentration of Fe vacancy after annealing in ultra high vacuum (UHV) by STM. They found by the STM images that the $\mathrm{Fe}_{1-x} \mathrm{O}$ surface consists of a mesh-like structure (surface super lat- tices). However, those STM images may indicate electronic structures on the surface, that is, the density of states on Fermi level rather than atomic arrangements.

In this paper, the surface crystal structure and the composition of polycrystalline $\mathrm{Fe}_{1-x} \mathrm{O}$ after annealing in UHV were analyzed at room temperature using LEED, AES as well as STM.

\section{Experimental Procedure}

\subsection{Sample Preparation}

The $\mathrm{Fe}_{1-x} \mathrm{O}$ sample was prepared from the oxidation of an electrolytic iron strip $(1 \mathrm{~mm} \times 25 \mathrm{~mm} \times 40 \mathrm{~mm}, 99.99 \%$ purity). The iron strip was suspended using a platinum wire in a $\mathrm{SiC}$ resistance furnace and equilibrated at $1473 \mathrm{~K}$ for $48 \mathrm{~h}$ in the flowing gas mixture of $\mathrm{CO}_{2}(45 \mathrm{~mL} / \mathrm{min})$ and $\mathrm{CO}(45 \mathrm{~mL} / \mathrm{min})\left(P_{\mathrm{CO}_{2}} / P_{\mathrm{CO}}=1\right.$, which is in equilibrium with the oxygen partial pressure of $\left.1.1 \times 10^{-11} \mathrm{~atm}\right)$. This condition was chosen to produce $\mathrm{Fe}_{0.92} \mathrm{O}$ from $\mathrm{FeO}-\mathrm{Fe}_{2} \mathrm{O}_{3}$ phase diagram. ${ }^{10)}$ The oxidized iron strip was then quenched to room temperature by dropping it to the bottom of the furnace and spraying argon gas onto it.

The phase and the lattice parameter of the oxidized sample were determined by using the XRD technique (Rigaku Co. RINT-TTR-3C/PC) and confirmd to be $\mathrm{Fe}_{1-x} \mathrm{O}$. The lattice parameter of $\mathrm{Fe}_{1-x} \mathrm{O}$ was calculated by means of the Nelson-Riley function, using diffraction peaks of (111), (200), (220), (311), (222), (400), (331) and (420). The density of the $\mathrm{Fe}_{1-x} \mathrm{O}$ sample was determined by means of the Archimedean method.

The $\mathrm{Fe}_{1-x} \mathrm{O}$ sample was cut in pieces and polished with emery paper with several different grids and finally with diamond paste with a grain size of $0.5 \mu \mathrm{m}$. It was then rinsed in acetone using an ultrasonic bath for $30 \mathrm{~min}$. 


\subsection{Observation of Surface}

The surface of the $\mathrm{Fe}_{1-x} \mathrm{O}$ sample was analyzed in an UHV chamber equipped with STM (Unisoku Co. USM1100SX3) and LEED/AES optics (OCI Inc. BDL800IR). The $\mathrm{Fe}_{1-x} \mathrm{O}$ sample was annealed to obtain the clean surface at $1273 \mathrm{~K}$ for $4 \mathrm{~min}$ under the total pressure of $1.3 \times 10^{-6} \mathrm{~Pa}$ by passing a direct current through the sample. The temperature of the sample was measured by a twocolor pyrometer through the quartz window of the chamber. After the sample was rapidly cooled down to room temperature, STM, LEED and AES analyses were performed. The tungsten tips were fabricated by electochemical etching in an aqueous $\mathrm{KOH}$. The tips were cleaned by electronic heat radiation in the UHV chamber $\left(2.7 \times 10^{-8} \mathrm{~Pa}\right)$ and were subsequently used for the STM observation. All STM data were obtained in the constant current mode. The incident electron beam for LEED was applied in perpendicular to the $\mathrm{Fe}_{1-x} \mathrm{O}$ surface, and the images of the LEED patterns were obtained using a digital camera. The same electron gun and the optical system were utilized for AES as well as LEED. The retarding field analyzer (RFA) was used for analyzing the electron energies. The total pressures during LEED and STM measurements were fixed in $2.7 \times 10^{-8}$ and $5.3 \times 10^{-9} \mathrm{~Pa}$, respectively.

\section{Results}

\subsection{Determination of $x$ in $\mathrm{Fe}_{1-x} \mathrm{O}$ Sample}

The polycrystalline iron oxide samples had the grain size of about 2-4 mm and were confirmed to be wüstite $\left(\mathrm{Fe}_{1-x} \mathrm{O}\right)$ by XRD. The non-stoichiometric number, $x$, in $\mathrm{Fe}_{1-x} \mathrm{O}$ is calculated by the following equation ${ }^{11)}$ :

$$
x=\frac{M_{\mathrm{FeO}}}{M_{\mathrm{Fe}}} \cdot \frac{d_{\mathrm{cal}}-d_{\mathrm{meas}}}{d_{\mathrm{cal}}}=\frac{M_{\mathrm{FeO}}}{M_{\mathrm{Fe}}} \cdot M_{\mathrm{V}^{\prime \prime}}
$$

where $d_{\text {cal }}$ is the theoretical density that is derived from the lattice parameter, $a_{0}, d_{\text {meas }}$ is the observed density that is determined by the Archimedian method, $M_{\mathrm{V}^{\prime \prime}}$ is the mass percent concentration of Fe vacancy, and $M_{i}$ is molecular weight of component $i$. Table 1 shows the results of the calculation, and $x$ is $0.10 . x$ is estimated to be 0.08 in case of $a_{0}=4.297 \AA$, which is the obtained lattice parameter, from the relationship between $x$ and lattice parameter. ${ }^{12)}$ It was concluded that $x$ of the sample used in the present study is $\mathrm{Fe}_{0.91} \mathrm{O}($ i.e. $x=0.09( \pm 0.01))$.

\subsection{Polycrystalline $\mathrm{Fe}_{0.91} \mathrm{O}$ Surface after Annealing in UHV}

\subsubsection{AES Spectra of $\mathrm{Fe}_{0.91} \mathrm{O}$}

Figure 1 shows the AES spectrta of the $\mathrm{Fe}_{0.91} \mathrm{O}$ surface after annealing at $1273 \mathrm{~K}$ in UHV. All peaks are assigned to the Fe and $\mathrm{O}$ spectra. After the heat treatment at $1273 \mathrm{~K}$ in the UHV chamber, all contaminations were removed successfully to below the detection limit of the AES analyzer.

\subsubsection{STM Image of $\mathrm{Fe}_{0.91} \mathrm{O}$}

The STM image of the $\mathrm{Fe}_{0.91} \mathrm{O}$ surface is shown in Fig. 2 and Fig. 3. Many steps with the zigzag shaped edges were formed on the surface after annealing in Fig. 2. The ob-
Table 1. Characterization of bulk $\mathrm{Fe}_{1-x} \mathrm{O}$.

\begin{tabular}{ccccc}
\hline$a_{0} / \AA$ & $d_{\text {cal }} / \mathrm{g} \cdot \mathrm{cm}^{-3}$ & $d_{\text {meas }} / \mathrm{g} \cdot \mathrm{cm}^{-3}$ & $M_{V^{\prime \prime}}(\%)$ & $1-x$ \\
\hline \hline 4.297 & 6.03 & 5.55 & 7.69 & 0.90 \\
\hline
\end{tabular}

(a)

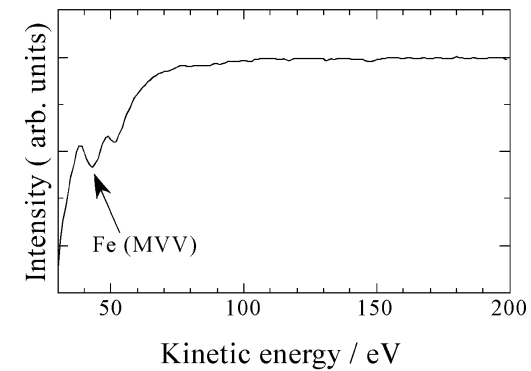

(b)

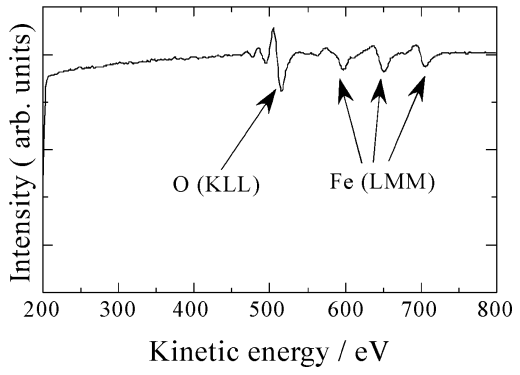

Fig. 1. AES spectra of $\mathrm{Fe}_{0.91} \mathrm{O}$ surface measured after annealing at $1273 \mathrm{~K}$.

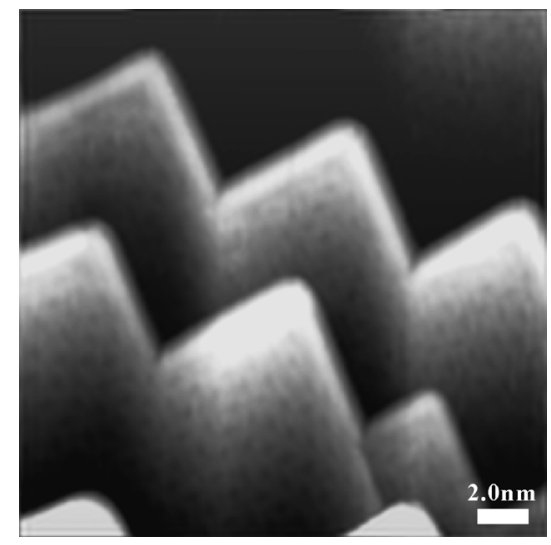

Fig. 2. Constant current STM image of $\mathrm{Fe}_{0.91} \mathrm{O}$ surface annealed at $1273 \mathrm{~K}$ for $4 \mathrm{~min} .20 .7 \mathrm{~nm} \times 20.7 \mathrm{~nm}$ scanning range, $0.35 \mathrm{~V}$ sample bias, $0.14 \mathrm{nA}$ tunneling current.

served minimum step height was $0.5 \mathrm{~nm}$ in the present study. The step height ranged in $0.5 \mathrm{~nm}$ and $1.5 \mathrm{~nm}$. The mesh-like structure was observed on the terrace. The periodicity of each mesh was about $0.8-1.3 \mathrm{~nm}$, which is 2 to 3 fold longer than the lattice parameter of wüstite. The depth of the mesh has been measured as $c a .0 .05 \mathrm{~nm}$, however, in fact it may be deeper because the apex of tips has curvature. Though most of the edges of the steps were zigzag in shape, linear edges were sometimes observed as shown in Fig. 3. The step height and the mesh-like structure on the terrace were the same as the crystals with the zigzag edges in Fig. 2.

\subsubsection{LEED Analysis}

The LEED patterns from the $\mathrm{Fe}_{0.91} \mathrm{O}$ surface after anneal- 

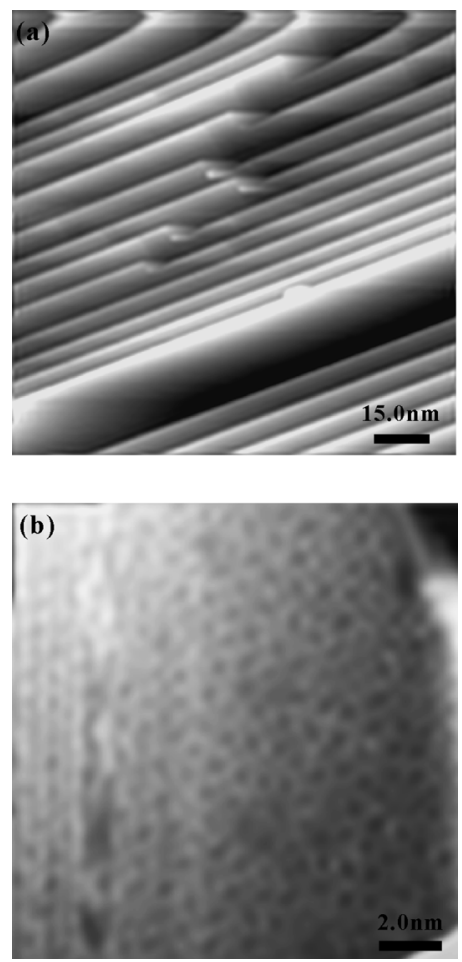

Fig. 3. Constant current STM image of $\mathrm{Fe}_{0.91} \mathrm{O}$ surface annealed at $1273 \mathrm{~K}$ for $4 \mathrm{~min}$ on the other grain. (b) is magnified image of (a). (a) $119.4 \mathrm{~nm} \times 119.4 \mathrm{~nm}$ scanning range, $0.33 \mathrm{~V}$ sample bias, $0.12 \mathrm{nA}$ tunneling current. (b) $15.9 \mathrm{~nm} \times 15.9 \mathrm{~nm}$ scanning range, 0.50 sample bias, $0.12 \mathrm{nA}$ tunneling current.

ing is shown in Fig. 4 with the different beam energies. When the beam energy increases, two subsets of the spots individually move toward certain spots as the Ewald sphere becomes larger. Consequently, two subsets of the diffraction images, as indicated as A and B in Fig. 5, were identified. The two spots which remained stationary throughout the experiment, whilst the other spots moved towards it, were labelled (00) for each set of diffraction pattern. Thus two sets of diffraction patterns appear to be superimposed in this figure. In other areas of the sample, more than 2 patterns were superimposed in the LEED patterns. In such cases, the incident electron beam might radiate several grains. The square lattice is the pattern from (001) plane of $\mathrm{Fe}_{1-x} \mathrm{O}$ which has the rock-salt type crystal structure. Therefore the streaks were parallel to $\langle 110\rangle$ direction of $\mathrm{Fe}_{1-x} \mathrm{O}$. No additional spots were observed except the basic reflection from (001) of the bulk wüstite.

\section{Discussion}

\subsection{Facet Growth of Polycrystalline $\mathrm{Fe}_{1-x} \mathrm{O}$ Surface by Annealing}

The only basic reflection from (001) of bulk is obtained in the LEED patterns of the polycrystalline $\mathrm{Fe}_{1-x} \mathrm{O}$ after annealing in UHV. The (001) facet was formed on the surface during the heat treatment. From the view point of electroneutrality, the (001) surface is the most stable structure in the case of rock-salt structure. Thus, each grain faces the (001) by forming the facet structure.

The streak in the LEED pattern is derived from the arrangement of parallel steps on the surface. When the
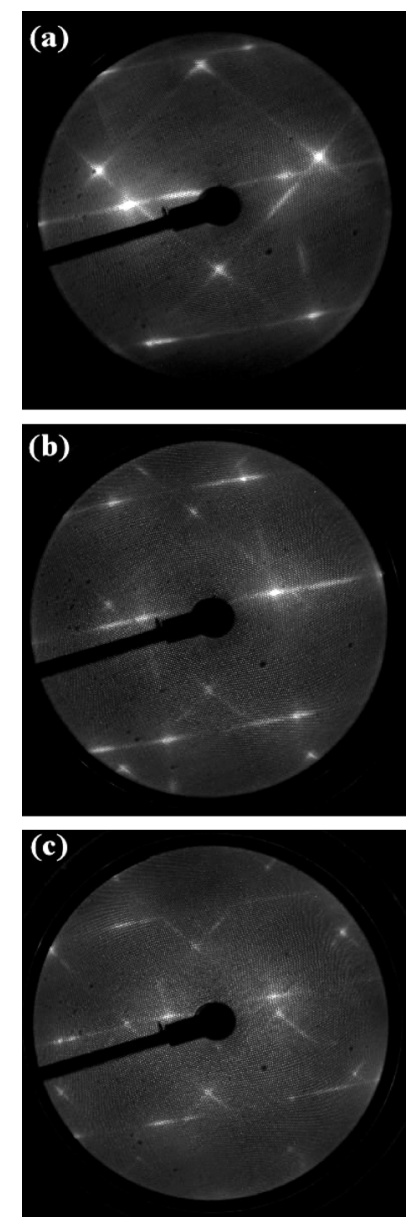

Fig. 4. Transition of LEED patterns of $\mathrm{Fe}_{0.91} \mathrm{O}$ surface obtained after annealing at $1273 \mathrm{~K}$ for $4 \mathrm{~min}$ with the change of incident electron energy of (a) $42.4 \mathrm{eV}$, (b) $61.1 \mathrm{eV}$ and (c) $90.9 \mathrm{eV}$.

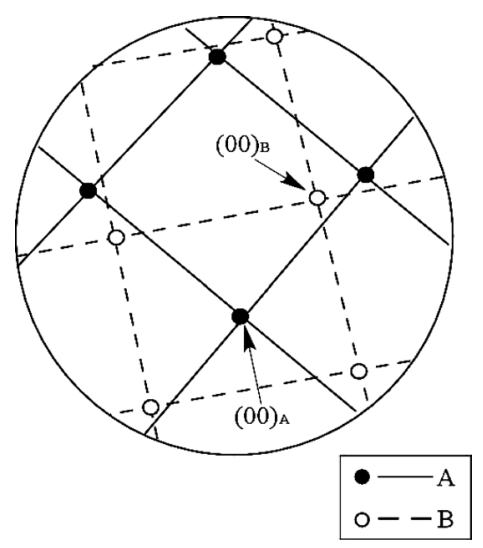

Fig. 5. Schematic illustration of LEED pattern determintied specular reflection of A and B in Fig. 4(a).

steps are parallel with varying widths, the electrons scattered from the same terrace are in phase, however, the scattering from separate terraces are out-of-phase. In such a case, the diffraction spots can be streaked. ${ }^{13)}$ In the present study, it is considered that the step direction in the STM image is the $\langle 110\rangle$ because the streaks sit along the square diffraction pattern. 


\subsection{Long-period Structure on the Terrace of $\mathrm{Fe}_{1-x} \mathrm{O}$ Surface}

The periodicity of the 'mesh-like' structure on the terraces, which is shown in Figs. 2 and 3(b), was about $0.8-1.3 \mathrm{~nm}$. Non-stoichiometric $\mathrm{Fe}_{1-x} \mathrm{O}$ has Fe vacancies aggregating to make clusters consisting of the Fe vacanccies, $\mathrm{Fe}^{3+}$ ions and $\mathrm{O}^{2-}$ ions. ${ }^{14)}$ The clusters are arrayed in lengths which are 2.5-2.7 times longer than the lattice parameter of the fundamental cell in a bulk. ${ }^{15)}$ The mesh-like structure may represent the density of states on the Fermi level of the defect clusters because the cluster periodicity is in agreement with the spacing of the 'mesh' in the STM image. At this stage it cannot be concluded that the meshlike structure is a result of surface topography or due to the density of states. The AES spectra revealed that the $\mathrm{Fe}_{0.91} \mathrm{O}$ surface consists of $\mathrm{Fe}$ and $\mathrm{O}$ atoms after annealing at $1273 \mathrm{~K}$ in UHV. The surface structures on the bulk of the metallic iron ${ }^{16,17)}$ and other compounds such as $\mathrm{Fe}_{3} \mathrm{O}_{4}{ }^{18-22)}$ and $\mathrm{Fe}_{2} \mathrm{O}_{3},{ }^{23-25)}$ have been investigated on the various crystallographic orientations. None of these reported structures are in agreement with the results obtained in this study. Consequently, the $\mathrm{Fe}_{0.91} \mathrm{O}$ sample was not oxidized and reduced by annealing in UHV performed before the surface observation. The defects in $\mathrm{Fe}_{1-x} \mathrm{O}$ derived from nonstoichiometry make clusters ${ }^{14)}$ and these clusters may be observed as a mesh-like structure in the STM images. No clear spots attributed to the super-lattice may be appeared in the LEED patterns owing to the overlap of the patterns from several grains and the streak from many steps on the surface as the background.

\section{Conclusion}

The surface of the polycrystalline $\mathrm{Fe}_{0.91} \mathrm{O}$ after anealing at $1273 \mathrm{~K}$ in UHV was observed using STM, LEED and AES. The (001) facet is formed, and many steps like zigzag shape in parallel with $\langle 110\rangle$ is arranged on the $\mathrm{Fe}_{0.91} \mathrm{O}$ surface. The mesh-like superstructure, which is considered as the arrangement of the defect clusters, exists on the terrace with period of about $0.8-1.3 \mathrm{~nm}$.

\section{REFERENCES}

1) T. Yamashita, T. Nakada and K. Nagata: Metall. Mater. Trans. B, 38 (2007), 185.

2) Y. J. Kim, C. Westphal, R. X. Ynzunza, Z. Wang, H. C. Galloway, M. Salmeron, M. A. Van Hove and C. S. Fadley: Surf. Sci., 416 (1998), 68.

3) S. Shaikhutdinov, M. Ritter and W. Weiss: Phys. Rev., B62 (2000), 7535 .

4) G. Ketteler and W. Ranke: J. Phys. Chem., B107 (2003), 4320.

5) C. Leygraf and S. Ekelund: Surf. Sci., 40 (1973), 609.

6) G. W. Simmons and D. J. Dwyer: Surf. Sci., 48 (1975), 373.

7) A. J. Pignocco and G. E. Pellissier: J. Electrochem. Soc., 112 (1965), 1188.

8) D. Cappus, M. Haßel, E. Neuhaus, M. Heber, F. Rohr and H.-J. Freund: Surf. Sci., 337 (1995), 268.

9) K. Nagata and K. Kitamura: Collected Abstracts of the $1999 \mathrm{Au}-$ tumn Meeting of the Japan Inst. Metals, (2004), 232.

10) A. Muan and E. F. Osborn: Phase Equilibria among Oxides in Steelmaking, Addison-Wesley, Massachusetts, (1965), 28.

11) K. Nagata and K. Goto: Bull. Jpn. Inst. Met., 26 (1987), 32.

12) L. von Bogdandy and H. J. Engell: The Reduction of Iron Ores, Springer-Verlag, Berlin, (1971), 29.

13) M. Henzler: Appl. Phys., 9 (1976), 11.

14) F. Koch and J. B. Cohen: Acta Cryst., B25 (1969), 275.

15) P. J. Manenc: J. Phys. Radium, 24 (1963), 447.

16) H. Tamura, T. Yamada and T. Mizoguchi: CAMP-ISIJ, 20 (2007), 1248.

17) T. Yamada, H. Tamura, T. Irisawa and T. Mizoguchi: CAMP-ISIJ, 20 (2007), 1247.

18) S. F. Ceballos, G. Mariotto, K. Jordan, S. Murphy, C. Seoighe and I. V. Shvets: Surf. Sci., 548 (2004), 106.

19) R. Jansen, V. A. M. Brabers and H. van Kempen: Surf. Sci., 328 (1995), 237.

20) Y. Oda, S. Mizuno, S. Todo, E. Torikai and K. Hayakawa: Jpn. J. Appl. Phys., 37 (1998), 4518.

21) A. R. Lennie, N. G. Condon, F. M. Leibsle, P. W. Murray, T. M. Parker, G. Thornton and D. J. Vaughan: Phys. Rev., B53 (1996), 10244.

22) N. G. Condon, F. M. Leibsle, T. M. Parker, A. R. Lennie, D. J. Vaughan and G. Thornton: Phys. Rev., B55 (1997), 15885.

23) N. G. Condon, P. W. Murray, F. M. Leibsle, G. Thornton, A. R. Lennie and D. J. Vaughan: Surf. Sci., 310 (1994), L609.

24) N. G. Condon, F. M. Leibsle, A. R. Lennie, P. W. Murray, D. J. Vaughan and G. Thornton: Phys. Rev. Lett., 75 (1995), 1961.

25) N. G. Condon, F. M. Leibsle, A. R. Lennie, P. W. Murray, T. K. Parker, D. J. Vaughan and G. Thornton: Surf. Sci., 397 (1998), 278. 